\title{
Social Behavioral Problems and the Health-Related Quality of Life in Children and Adolescents with Epilepsy
}

\author{
Hee-Yeon Choi ${ }^{1}$, Song E Kim² ${ }^{2}$ Hyang Woon Lee ${ }^{2}$, and Eui-Jung Kim ${ }^{1 凶}$ \\ ${ }^{1}$ Department of Psychiatry, Ewha Womans University School of Medicine, Seoul, Republic of Korea \\ ${ }^{2}$ Department of Neurology, Ewha Womans University School of Medicine, Seoul, Republic of Korea
}

Objective The purpose of this study was to investigate the impact of specific behavioral problems on the health-related quality of life (HRQOL) in children and adolescents with epilepsy.

Methods Children and adolescents with epilepsy ( $n=92$; age range $=6-17$ years) and their mothers completed questionnaires about behavioral problems, HRQOL, socio-demographics, and epilepsy-related variables. To determine significant predictor variables of the HRQOL, the stepwise regression analyses and partial correlations were performed to adjust for other behavioral problems and covariates.

Results The analyses revealed that an increase in social behavioral problems and delinquent behavior was associated with a decrease in the HRQOL. Lower levels of maternal education and the number of antiepileptic drugs were also associated with a decline in the HRQOL; the HRQOL and social behavioral problems remained significantly correlated after adjusting for maternal education level, number of antiepileptic drugs, and non-social behavioral problems.

Conclusion Parents and practitioners should provide intervention if behavioral problems, particularly social behavioral problems, are observed in children or adolescents with epilepsy.

Psychiatry Investig 2016;13(5):488-495

Key Words Epilepsy, Health-related quality of life, Behavioral problem, Child, Adolescent.

\section{INTRODUCTION}

Epilepsy is a common chronic illness of childhood. Traditionally, clinicians have focused on treating the physical aspects of epilepsy; however, there are other factors, including psychological facets, which can also affect the health-related quality of life (HRQOL). Research using HRQOL assessments in chronic disease has had important implications for epilepsy management and overall outcomes. It has been found that children and adolescents with epilepsy have a lower HRQOL than healthy controls ${ }^{1}$ and an increased risk for maladjustment and poor quality of life (QOL) in different domains than do children with other chronic health problems, such as diabetes or asthma. ${ }^{2-4}$ Psychological or psychosocial problems, such as

Received: December 30, 2015 Revised: March 7, 2016

Accepted: March 21, 2016 Available online: September 12, 2016

$\triangle$ Correspondence: Eui-Jung Kim, MD, PhD

Department of Psychiatry, Ewha Womans University, Mokdong Hospital, 1071 Anyangcheon-ro, Yangcheon-gu, Seoul 07985, Republic of Korea Tel: +82-2-2650-5164, Fax: +82-2-2650-2649, E-mail: christie@ewha.ac.kr

(ac) This is an Open Access article distributed under the terms of the Creative Commons Attribution Non-Commercial License (http://creativecommons.org/licenses/bync/3.0) which permits unrestricted non-commercial use, distribution, and reproduction in any medium, provided the original work is properly cited. emotional, behavioral, or environmental problems and social stigma, are faced by children and adolescents with epilepsy. ${ }^{5-7}$

In a recent study, it was hypothesized that psychological comorbidity, child characteristics, and environmental factors influence epileptic outcomes more than epilepsy-specific variables. ${ }^{8}$ Ferro et al. ${ }^{9}$ reported that behavioral and cognitive problems in children with epilepsy are the strongest predictive factors of the HRQOL. Studies have shown that the prevalence of behavioral problems in pediatric epilepsy ranges from $16 \%$ to $77 \% \%^{10,11}$ compared with $9 \%$ in the general pediatric population. ${ }^{12}$ Thus, children with epilepsy and emotional or behavioral problems tend to have both a poor epilepsy outcome and reduced QOL. Stevanovic et al. ${ }^{13}$ and Adewuya and Oseni ${ }^{14}$ reported that depression and anxiety disorders were strong predictors of the QOL in children and adolescents with epilepsy. Malhi and Singhi ${ }^{15}$ found that total psychopathology scores were significant predictors of QOL in pediatric epilepsy.

While recent studies have investigated factors influencing the HRQOL, few studies have evaluated which particular behavioral problems contributing to the HRQOL in children and adolescents with epilepsy in Korea. The purpose of current study examined the impact of behavioral problems, socio-de- 
mographics, and epilepsy-related variables on the HRQOL of Korean children and adolescents with epilepsy and identified the behavioral problems associated with the HRQOL controlling other significant variables. In addition, we examined the differences in awareness of HRQOL between children and adolescents with epilepsy and their parents. The identification of specific behavioral problems with impact on life outcomes may assist parents and practitioners in recognizing and supplying appropriate interventions to increase the HRQOL for children and adolescents with epilepsy.

\section{METHODS}

\section{Participants}

Children and adolescents ( $n=92$; age range $=6-17$ years), who had been diagnosed and treated for epilepsy, were recruited at the epilepsy clinics of Ewha Womans University Mokdong Hospital to participate in this study. Inclusion criteria, in addition to the clinical diagnosis of epilepsy, were: 1) elementary, middle, or high school students able to understand and answer the questionnaires and; 2) the absence of severe neurological impairments, sequelae of traumatic brain damage in brain magnetic resonance imaging (MRI), combined psychiatric disorders [e.g., psychotic disorder, autism spectrum disorder or attention deficit/hyperactivity disorder (ADHD)], mental retardation, or other chronic illness. The mothers of the participants were also included in the study.

To exclude cognitive problems and combined psychiatric disorders that could influence the HRQOL, children and adolescents with epilepsy tested the Korean-Wechsler Intelligence Scale for children and examined brain MRI scans. Also participants checked the Child Depression Inventory and Children's Manifest Anxiety Scale-Revised. Mothers of participants checked the Conner's Parent Rating Scales. And then, child psychiatrist interviewed participants who have combined psychiatric problems at a clinical level. Of the 122 children and adolescents screened, 5 with a full-scale IQ of lower 70 on the Korean-Wechsler Intelligence Scale for children, five with sequelae of traumatic brain injury in brain MRI, sixteen with $\mathrm{ADHD}$ on the Conner's Parent Rating Scales and psychiatric interview with child psychiatrist, and four with incomplete questionnaires were excluded.

\section{Measures}

After outpatient examination at epilepsy clinic, neurologist explained to the patients and their mothers the purpose of the study, obtained their informed consent, and administered a self-report questionnaire to the patients and their mothers, under guidance. The self-report questionnaires for children under the age of 13 were age appropriately adapted. A trained research nurse assisted children and adolescents in completing the self-report questionnaires when necessary.

Socio-demographic information, such as the level of maternal education, parent's marital status, and family income, was collected from the mothers. We also gathered information on epilepsy-related variables, such as age at epilepsy onset, epilepsy duration, type of seizure, etiology of seizure, frequency of seizures, and type and number of antiepileptic drugs from interview of neurologist and medical files.

The HRQOL of children and adolescents with epilepsy was assessed using the Health-Related Quality of Life in Children with Epilepsy questionnaire developed by Ronen. ${ }^{16}$ This HRQOL instrument was chosen due to its parallel measures for children (the Child Self-Report Scale) and parents (the Parent-Proxy Response Scale), which allows both child and parent perceptions of the QOL ${ }^{16}$; a few studies comparing child and parent report of the QOL have found that children and parents had different perspectives of the QOL for children with epilepsy. ${ }^{17-19}$ The scales include the domains of Interpersonal/Social Consequences, Worries and Concerns, Intrapersonal/Emotional Issues, Epilepsy My Secret, and Quest for Normality. ${ }^{20}$ On the parent scale, Worries and Concerns include both present and future worries, which are not part of the child scale. The Quest for Normality domain, which is only present on the child scale, includes issues about the ability to live a normal life and treatment by peers and family. Each scale has five subscales with a possible score of 5-20 for each subscale. The total the HRQOL score is the sum of all the parent and child responses. Thus, the total score for both parent and child scales ranges from 50 to 200, and higher total HRQOL scores reflect a better HRQOL. In this study, participants and their mothers checked the Child Self-Report Scale and Parent-Prosy Response Scale of the HRQOL in Children with Epilepsy questionnaire respectively.

The Child Behavior Checklist (CBCL) has been commonly used to evaluate behavioral problems in children and adolescents with epilepsy. ${ }^{5,21}$ The Korean version of the CBCL, which has been standardized in Korea, ${ }^{22,23}$ was used to measure behavioral problems. The checklist is a 118-item scale on which parents rate their children's behavioral problems during the past 6 months. Each item is rated on a 3-point scale: 0 (not true), 1 (somewhat or sometimes true), and 2 (very true or often true). It is composed two subscales: the Broadband scale, which consists of internalizing problems, externalizing problems, and total behavior problems; and the Syndrome scale, which contains eight further subscales (anxious/depressed, withdrawn, somatic complaints, aggressive behavior, delinquent behavior, thought problems, attention problems, and social problems). Raw scores for the behavioral problems are converted to a standardized $t$ score and normed for age and 
gender. In this study, mothers of participants completed the CBCL. The total behavior problem score, based on the t scores, included the internalizing, externalizing, thought, attention, and social problems subscales. For the syndrome scales, the atrisk range was defined as $t>67$ and the clinical range was defined as $\mathrm{t}>70 .^{22,23}$

\section{Data analyses}

T-tests and one-way analysis of variance (ANOVA) were also used to examine differences in the total HRQOL scores for discrete variables. To determine significant predictor variables of the HRQOL, Pearson correlation analysis was performed for continuous variables. Predictor variables included socio-demographic variables, epilepsy-related variables, and the eight subscales of CBCL.

Table 1. Socio-demographic and clinical characteristics of participants $(\mathrm{N}=92)$

\begin{tabular}{|c|c|c|c|}
\hline & \multicolumn{2}{|c|}{ The total HRQOL questionnaire score } & \multirow{2}{*}{$\mathrm{p}$} \\
\hline & $\mathrm{N}(\%)$ & Mean \pm SD & \\
\hline \multicolumn{4}{|l|}{ Socio-demographic variables } \\
\hline $\operatorname{Sex}^{*}$ & & & 0.60 \\
\hline Male & $53(58)$ & $153.02 \pm 18.43$ & \\
\hline Female & $39(42)$ & $150.97 \pm 17.45$ & \\
\hline Age (years) ${ }^{\dagger}$ & $92(100)$ & $12.15 \pm 3.27$ (range: $6-17)$ & $0.94^{*}$ \\
\hline Maternal education level ${ }^{\ddagger}$ & & & 0.014 \\
\hline$\leq$ Middle school & $7(7.6)$ & $133.71 \pm 28.24$ & \\
\hline$\geq$ High school & $52(56.5)$ & $152.34 \pm 15.80$ & \\
\hline$\geq$ College & $33(35.9)$ & $154.67 \pm 16.34$ & \\
\hline Family income $(\nVdash, \text { million })^{\ddagger}$ & & & 0.46 \\
\hline Low $(\leq 2)$ & $21(22.8)$ & $147.75 \pm 20.85$ & \\
\hline Middle (2-5) & $62(67.4)$ & $153.58 \pm 17.69$ & \\
\hline High $(5 \leq)$ & $9(9.8)$ & $152.50 \pm 10.78$ & \\
\hline \multicolumn{4}{|l|}{ Epilepsy-related variables } \\
\hline Age at epilepsy onset (years) ${ }^{\dagger}$ & $92(100)$ & $8.22 \pm 3.88$ & $0.77^{*}$ \\
\hline 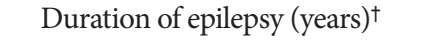 & $92(100)$ & $2.91 \pm 2.47$ & $0.89^{*}$ \\
\hline Seizure frequency (past year)* & & & 0.91 \\
\hline Seizure-free & $30(32.6)$ & $152.48 \pm 13.63$ & \\
\hline$\geq 1$ & $62(67.4)$ & $152.00 \pm 19.84$ & \\
\hline Type of seizure ${ }^{\ddagger}$ & & & 0.18 \\
\hline Generalized & $43(46.7)$ & $154.46 \pm 15.02$ & \\
\hline Complex partial & $19(20.7)$ & $145.47 \pm 19.58$ & \\
\hline Others & $30(32.6)$ & $153.32 \pm 20.19$ & \\
\hline Etiology of seizures ${ }^{\ddagger}$ & & & 0.25 \\
\hline Idiopathic & $22(23.9)$ & $155.36 \pm 16.19$ & \\
\hline Cryptogenic & $37(40.2)$ & $154.68 \pm 16.48$ & \\
\hline Familial & $8(8.7)$ & $148.13 \pm 24.46$ & \\
\hline Symptomatic & $19(20.7)$ & $145.74 \pm 19.9$ & \\
\hline Number of antiepileptic drugs ${ }^{\ddagger}$ & & & 0.047 \\
\hline None & $2(2.2)$ & $156.00 \pm 4.24$ & \\
\hline Monotherapy & $82(89.1)$ & $153.76 \pm 17.37$ & \\
\hline Ditherapy & $5(5.4)$ & $138.40 \pm 19.78$ & \\
\hline Polytherapy & $3(3.3)$ & $131.00 \pm 18.74$ & \\
\hline
\end{tabular}

${ }^{*}$ t-test analysis was performed, ${ }^{\dagger}$ Pearson correlation analysis was performed, ${ }^{\ddagger}$ analysis of variance was performed. HRQOL questionnaire: health-related quality of life in children with epilepsy questionnaire, SD: standard deviation 
Variables with statistically significant correlations $(\mathrm{p}<0.05)$ with the total HRQOL score were selected as independent variables for stepwise regression analyses. Three stepwise regression analyses (the total HRQOL, parent, and child scale scores) were performed to identify predictor variables from the behavioral, socio-demographic, and epilepsy-related measures. Qualitative dependent variables were converted to dummy variables for stepwise analysis. Eight partial correlations between each subscale of the CBCL and the total HRQOL were used to adjust for other behavioral problems and significant variables. Data were analyzed using Statistical Package for the Social Sciences (SPSS 20.0; SPSS Inc., Chicago, IL, USA); significance was set at 0.05 .

\section{RESULTS}

\section{Socio-demographic and epilepsy-related data}

The socio-demographic and epilepsy-related characteristics of the participants are shown in Table 1. The main antiepileptic drugs used included sodium valproate, carbamazepine, lamotrigine, and topiramate. Among the socio-demographic and epilepsy-related variables, there were two significant associations with the HRQOL: maternal education level $(\mathrm{p}=0.014)$ and number of antiepileptic drugs $(\mathrm{p}=0.012)$. A low maternal education level and an increased number of antiepileptic drugs were associated with a decline in the HRQOL of children and adolescents with epilepsy.

\section{The Health-Related Quality of Life and Child Behavior Checklist scores}

Table 2 shows the total and subdomain scores of the HRQOL questionnaire. There were no significant differences between the mean score of parent and child scales except in the intrapersonal/emotional subdomain. Mothers rated children's intrapersonal/emotional QOL higher than the children and adolescents with epilepsy did.

Table 2. The total and 6 subdomains scores of the HRQOL questionnaire

\begin{tabular}{|c|c|c|c|c|}
\hline & \multicolumn{3}{|c|}{ The HRQOL questionnaire (Mean \pm SD) } & \multirow{2}{*}{$\mathrm{p}^{*}$} \\
\hline & Total score & CSRS score & PPRS score & \\
\hline Total HRQOL & $152.16 \pm 17.95$ & $74.75 \pm 11.39$ & $77.26 \pm 9.86$ & \\
\hline \multicolumn{5}{|l|}{ Subdomain of HRQOL } \\
\hline Interpersonal/social & $30.52 \pm 5.83$ & $15.28 \pm 3.35$ & $15.49 \pm 2.96$ & 0.530 \\
\hline Present worries & $29.34 \pm 5.31$ & $14.44 \pm 3.62$ & $15.17 \pm 2.75$ & 0.089 \\
\hline Future worries & $16.80 \pm 3.02$ & - & $16.80 \pm 3.02$ & \\
\hline Intrapersonal/emotional & $28.36 \pm 5.65$ & $13.70 \pm 3.46$ & $14.87 \pm 2.83$ & 0.005 \\
\hline Epilepsy secrecy & $28.78 \pm 5.29$ & $14.31 \pm 2.99$ & $14.74 \pm 2.72$ & 0.221 \\
\hline Quest for normality & $16.92 \pm 2.82$ & $16.92 \pm 2.82$ & - & \\
\hline
\end{tabular}

*t-test was performed. CSRS includes interpersonal/social, present worries, intrapersonal/emotional, epilepsy secrecy, and quest for normality. PPRS includes interpersonal/social, present worries, future worries, intrapersonal/emotional, and epilepsy secrecy. SD: standard deviation, CSRS: Child-Self Response Scale, PPRS: Parent-Proxy Response Scale, HRQOL questionnaire: health-related quality of life in children with epilepsy questionnaire

Table 3. Correlations between the 8 subscales of CBCL and the HRQOL questionnaire

\begin{tabular}{lccc}
\hline \multicolumn{1}{c}{ The CBCL } & The CBCL & \multicolumn{2}{c}{ The HRQOL questionnaire, $\mathrm{r}$} \\
\cline { 2 - 3 } Subscales of CBCL & CBCL t score (mean \pm SD) & $-0.339^{* * *}$ \\
Withdrawn & $51.21 \pm 14.33$ & $-0.444^{* * *}$ & $-0.414^{* * *}$ \\
Somatic complaints & $52.40 \pm 8.91$ & $-0.281^{* *}$ & $-0.293^{* * *}$ \\
Anxious/depressed & $51.01 \pm 9.03$ & $-0.365^{* * *}$ & $-0.426^{* * *}$ \\
Social problems & $54.56 \pm 11.24$ & $-0.554^{* * *}$ & $-0.312^{* * *}$ \\
Thought problems & $52.23 \pm 8.69$ & $-0.459^{* * *}$ & $-0.526^{* * *}$ \\
Attention problems & $53.09 \pm 11.45$ & $-0.534^{* * *}$ & $-0.403^{* * *}$ \\
Delinquent behavior & $49.67 \pm 8.56$ & $-0.477^{* * *}$ & $-0.399^{* * *}$ \\
Aggressive behavior & $50.88 \pm 9.74$ & $-0.473^{* * *}$ & $-0.421^{* * *}$ \\
\hline
\end{tabular}

${ }^{* *} \mathrm{p}<0.01,{ }^{* * *} \mathrm{p}<0.001$. CBCL: Child Behavior Checklist, HRQOL questionnaire: health-related quality of life in children with epilepsy questionnaire, PPRS: Parent-Proxy Response Scale of the HRQOL questionnaire, CSRS: Child Self-Report Scale of the HRQOL questionnaire, SD: standard deviation 


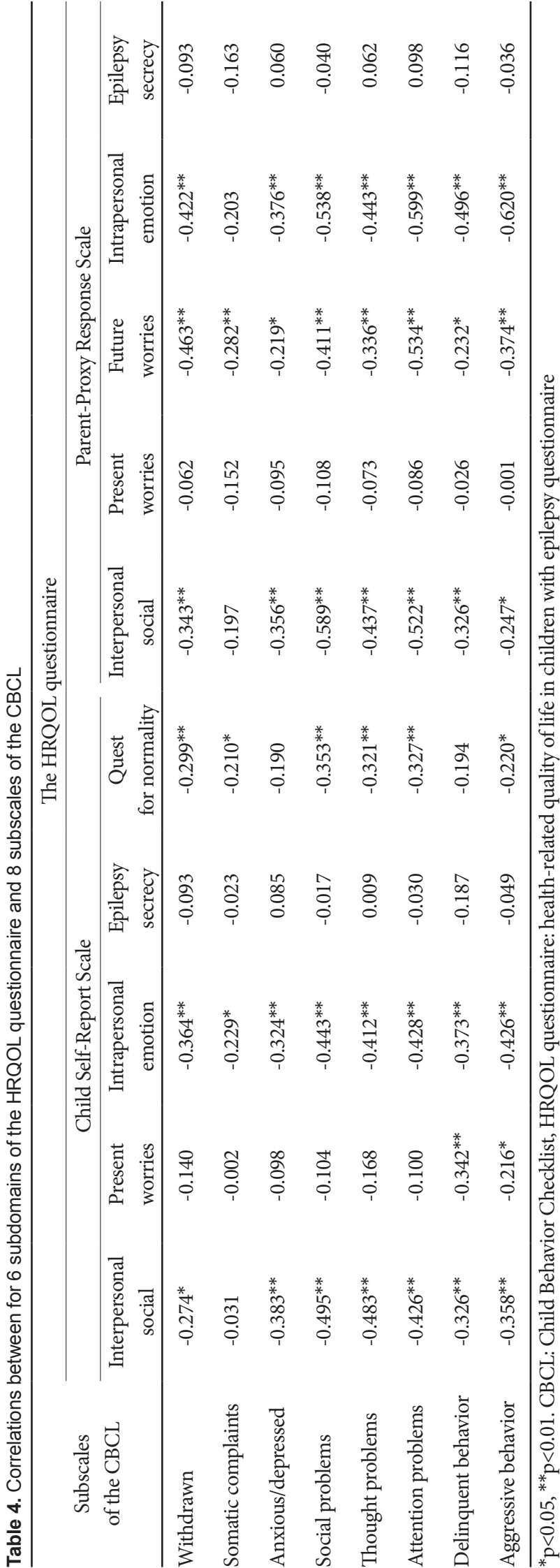

The mean $t$ scores for each of the eight subscales of the CBCL are in Table 3. There were moderate negative correlations between all eight subscales of the CBCL and the HRQOL questionnaire; this indicated increases in behavioral problems were associated with a decrease in the HRQOL.

The correlations between the six subdomains of the HRQOL and the eight subscales of the CBCL, presented separately for child and mother reports, are shown in Table 4. Almost all behavioral problems were negatively correlated with the HRQOL with the exception those in the epilepsy secrecy domain on the child scale and present worries and epilepsy secrecy on the parent scale.

\section{Significant variables associated with the health-related quality of life scores}

Partial correlation analysis adjusting for the significant predictors, maternal education level, and the number of antiepileptic drugs, showed the eight subscales of the CBCL had moderate negative correlations with the total HRQOL score: withdrawn ( $\mathrm{r}=-0.387, \mathrm{p}<0.001)$, somatic complaints $(\mathrm{r}=-0.254$, $\mathrm{p}=0.018)$, anxious/depressed $(\mathrm{r}=-0.339, \mathrm{p}=0.001)$, social problems $(\mathrm{r}=-0.483, \mathrm{p}<0.001)$, thought problems $(\mathrm{r}=-0.388$, $\mathrm{p}<0.001)$, attention problems $(\mathrm{r}=-0.467, \mathrm{p}<0.001)$, delinquent behavior $(\mathrm{r}=-0.413, \mathrm{p}<0.001)$, and aggressive behavior $(\mathrm{r}=$ $-0.424, \mathrm{p}<0.001)$. Only social behavioral problems had a significant negative correlation with the total HRQOL $(\mathrm{r}=-0.237$, $\mathrm{p}=0.035)$ after controlling for all other behavioral problems, maternal education level, and the number of antiepileptic drugs.

Stepwise regression analysis revealed that social behavioral problems, delinquent behavior, and maternal education level were significant predictors of the variation in the total HRQOL scores. The scale for children and adolescents showed similar pattern (Table 5). Social behavioral problems were a strong predictor of the HRQOL, and accounted for these accounted for $29.8 \%, 26.8 \%$, and $17.2 \%$ of the variance on the total, parent scale, and child scale scores, respectively.

\section{DISCUSSION}

The present study found significant negative correlations between the HRQOL in Children with Epilepsy and behavioral problems. The regression analysis identified social behavioral problems, delinquent behaviors, and maternal education level as significantly independent contributors to the variance in the HRQOL of children and adolescents with epilepsy. Children and adolescents also reported a significant association between the number of antiepileptic medications and the HRQOL. Mothers reported that social behavioral problems and somatic complaints were significantly associated with the HRQOL. 
Table 5. The 3 stepwise regression analyses for significant predictors of the HRQOL questionnaire

\begin{tabular}{|c|c|c|c|}
\hline & Standardized Coefficients Beta & Adjusted $\mathrm{R}^{2}$ & F change \\
\hline \multicolumn{4}{|l|}{ The total HRQOL questionnaire } \\
\hline 1. Social behavioral problems & $-0.554^{* * *}$ & 0.298 & $37.99^{* * *}$ \\
\hline 2. Social behavioral problems & $-0.421^{* * *}$ & 0.346 & $7.32^{* *}$ \\
\hline Delinquent behavior & $-0.270^{* * *}$ & & \\
\hline 3. Social behavioral problems & $-0.446^{* * *}$ & 0.395 & $7.76^{* *}$ \\
\hline Delinquent behavior & $-0.276^{* *}$ & & \\
\hline Maternal education level & $0.234^{* *}$ & & \\
\hline \multicolumn{4}{|l|}{ The Child Self-Report Scale } \\
\hline 1. Social behavioral problems & $-0.426^{* * *}$ & 0.172 & $19.06^{* * *}$ \\
\hline 2. Social behavioral problems & $-0.458^{* * *}$ & 0.235 & $8.04^{* *}$ \\
\hline Maternal education level & $0.268^{* *}$ & & \\
\hline 3. Social behavioral problems & $-0.318^{* *}$ & 0.290 & $7.58^{* *}$ \\
\hline Maternal education level & $0.274^{* *}$ & & \\
\hline Delinquent behavior & $-0.286^{* *}$ & & \\
\hline 4. Social behavioral problems & $-0.245^{*}$ & 0.314 & $4.00^{*}$ \\
\hline Maternal education level & $0.301^{* *}$ & & \\
\hline Delinquent behavior & $-0.306^{* *}$ & & \\
\hline Number of AEDs & $-0.192^{*}$ & & \\
\hline \multicolumn{4}{|l|}{ The Parent-Proxy Response Scale } \\
\hline 1. Social behavioral problems & $-0.526^{* * *}$ & 0.268 & $33.60^{* * *}$ \\
\hline 2. Social behavioral problems & $-0.481^{* * *}$ & 0.304 & $5.52^{*}$ \\
\hline Somatic complaints & $-0.212^{*}$ & & \\
\hline
\end{tabular}

We found that increased social behavioral problems appear to significantly impact the HRQOL of children and adolescents with epilepsy. This category included statements such as "acts too young for his/her age" and "socially immature and unsociable." Children's social functioning has been suggested as the best indicator of current and future behavioral and emotional problems ${ }^{24}$; an increased frequency of maladjustment, lower social skills, and social problems have been reported in pediatric epilepsy. ${ }^{4,25,26}$ Moreover, these problems were relatively more likely to affect children with epilepsy than their siblings or children with other chronic conditions. ${ }^{11}$ Our findings are consistent with previous results showing that children with epilepsy have more social problems and a lower QOL. ${ }^{27}$ Children with epilepsy may suffer from social difficulties and other attendant problems, such as emotional, thought (lower selfconcept or negative attitude toward epilepsy), adjustment (concealment of their condition or avoidance of age-appropriate activities), interpersonal/social, or cognitive problems. ${ }^{10,27-39}$ In particular, developmental tasks of school-age children are engaging with their peers and growing social skills. And socioculturally, Asians has socially oriented subjective well-being, while Euro-Americans have individually oriented subjective well-being. ${ }^{40}$ In recent cross-cultural study to evaluate differences in the life satisfaction between Korean and U.S. adolescents, satisfaction with school contributed significantly to global life satisfaction only for Korean adolescents. ${ }^{41}$ Therefore, these complex problems and factors may inhibit development and contribute to a decreased HRQOL for children and adolescents with epilepsy.

Our findings suggest that delinquent behavior and the level of maternal education are associated with the HRQOL; however, the explanatory power of these variables was relatively small. Similar to the results of other studies, ${ }^{3,42}$ delinquent behavior was relatively uncommon in our participants. Delinquent behaviors included having friends who are perceived as having a negative influence, lying, school refusal, and running away from home. Disruptive behaviors in children with epilepsy appear to have a negative impact on their overall functioning and may lead to a decrease in the HRQOL. Therefore, these findings suggest that clinicians need to be aware of the presence of delinquent behaviors in this population, even though these are relatively uncommon in children and adoles- 
cents with epilepsy.

In this study, low maternal education level was associated with a decreased HRQOL; this finding is consistent with the results of a previous studies ${ }^{15}$ that reported a low levels of in mothers' with children or adolescents with epilepsy was associated with a lack of knowledge, negative attitude, and uncertainty about epilepsy. ${ }^{4344}$ Therefore, mothers with low education may have inadequate parenting skills or low confidence and mastery in managing the epilepsy and behavior of their children, which may have a negative influence on children and family.

The polytherapy showed significantly negative association with HRQOL only in children and adolescents' report. This finding is consistent with previous studies that found an association between the QOL of children with epilepsy and the number of antiepileptic drugs. ${ }^{1,45}$ In recent studies, smaller number of medications showed a strong positive impact on quality of life in Korean pediatric epilepsy, ${ }^{46}$ and receiving polytherapy were independent factors predicting Korean adolescents with epilepsy's perception of stigma. ${ }^{47}$

Social behavioral problems, maternal education level, delinquent behavior, and the number of antiepileptic drugs demonstrated a significant negative impact of the HRQOL reported by the children and adolescents; these variables accounted for $31.4 \%$ of the variation in the HRQOL score. The pattern of these results was similar to the total HRQOL score. On the parent report, social behavioral problems and somatic complaints were the only significant predictors of the HRQOL. Delinquent behavior and level of maternal education were not significantly associated with the parent report scale, unlike their role as predictors of the total HRQOL and the child quality of life scales. In previous studies, internalizing problems, such as symptoms of depression and anxiety, were emphasized as strong predictors of the HRQOL for children and adolescents with epilepsy, ${ }^{13,14}$ whereas externalizing or other behavioral problems were not addressed relatively.

There were some differences observed between the parent and child HRQOL ratings in this study, which may have important clinical implications. First, discrepancies between parent and child reporting may reflect a different understanding or point of view of behavioral problems. The externalizing problems, delinquent and aggressive behaviors, have correlations with present worries only in the child report. Mothers of children and adolescents with epilepsy rated the intrapersonal/ emotion subdomain of the HRQOL higher than their children did. Thus, the emotional problems may be hiding other problems and delinquent behaviors that can be overlooked by mothers. At the same time, the somatic complaints could be overestimated in the parent's perspective, although even the higher parent ratings did not have a significant influence on the child's HRQOL score. These gaps could represent a double hardship for children and adolescents with epilepsy.

This study has several limitations. First, the subjects were recruited from a single university hospital; therefore, the results may not be generalizable to other settings. Second, there are various methodological limitations: the study was cross-sectional, had a small number of participants, no comparison group, and a heterogeneous seizure group. Third, our study used the CBCL as the tool to evaluate behavioral problems, instead of a more structured instrument. Although the CBCL is a well-standardized measure of behavioral problems in children and is commonly used in pediatric epilepsy, it has been reported to have a false-negative rate of $10 \%$ and a false-positive rate of $20 \%$ compared with the Diagnostic Interview Schedule for Children. ${ }^{48}$ Finally, the collinearity of the variables, especially among subscales of the CBCL, suggests that the results should be interpreted with caution. We assessed collinearity with the variance inflation factor and condition index in a regression model; all variance inflation factors were less than 2.0, which suggest there was no significant collinearity among predictors of the HRQOL.

Despite all these limitations, to close attention for the effects of specific behavioral problems on the HRQOL in children and adolescents with epilepsy in Korea. Especially, factors that impact on the behavioral problems, such as cognitive problems or ADHD, were excluded thorouthly. In addition, we estimated the HRQOL using a self-report measure that allowed independent ratings by children and a proxy report from their parents. This study demonstrated that social behavioral problems were significantly associated with the HRQOL for children and adolescents with epilepsy, even when other factors were controlled. Assessment and management of possible behavioral problems, especially social behavioral problems and delinquent behavior, are important to increase the HRQOL for children and adolescents with epilepsy. Targeted psychosocial interventions should be considered for children with epilepsy and social or delinquent behavior problems. In addition, appropriate education and support for parents of children with epilepsy is necessary and parents should be considered as part of the HRQOL management team for children and adolescents with epilepsy.

\section{REFERENCES}

1. Miller V, Palermo TM, Grewe SD. Quality of life in pediatric epilepsy: demographic and disease-related predictors and comparison with healthy controls. Epilepsy Behav 2003;4:36-42.

2. Austin JK, Smith MS, Risinger MW, McNelis AM. Childhood epilepsy and asthma: comparison of quality of life. Epilepsia 1994;35:608-615.

3. Austin JK, Huster GA, Dunn DW, Risinger MW. Adolescents with active or inactive epilepsy or asthma: a comparison of quality of life. Epilepsia 1996;37:1228-1238.

4. Moreira H, Carona C, Silva N, Frontini R, Bullinger M, Canavarro 
MC. Psychological and quality of life outcomes in pediatric populations: a parent-child perspective. J Pediatr 2013;163:1471-1478.

5. Austin JK, Dunn DW, Johnson CS, Perkins SM. Behavioral issues involving children and adolescents with epilepsy and the impact of their families: recent research data. Epilepsy Behav 2004;5(Suppl 3):S33-S41.

6. Jacoby A, Austin JK. Social stigma for adults and children with epilepsy. Epilepsia 2007;48(suppl 9):6-9.

7. MacLeod JS, Austin JK. Stigma in the lives of adolescents with epilepsy: a review of the literature. Epilepsy Behav 2003;4:112-117.

8. Ronen GM, Streiner DL, Boyle MH, Cunningham CE, Lach L, Verhey $\mathrm{LH}$, et al. Outcomes trajectories in children with epilepsy: hypotheses and methodology of a Canadian longitudinal observational study. Pediatr Neurol 2014;50:38-48.

9. Ferro MA, Camfield CS, Levin SD, Smith ML, Wiebe S, Zou G, et al. Trajectories of health-related quality of life in children with epilepsy: a cohort study. Epilepsia 2013;54:1889-1897.

10. Baker GA, Spector S, McGrath Y, Soteriou H. Impact of epilepsy in adolescence: a UK controlled study. Epilepsy Behav 2005;6:556-562.

11. Rodenburg R, Stams GJ, Meijer AM, Aldenkamp AP, Deković M. Psychopathology in children with epilepsy: a meta-analysis. J Pediatr Psychol 2005;30:453-468.

12. Davies S, Heyman I, Goodman R. A population survey of mental health problems in children with epilepsy. Dev Med Child Neurol 2003;45:292-295.

13. Stevanovic D, Jancic J, Lakic A. The impact of depression and anxiety disorder symptoms on the health-related quality of life of children and adolescents with epilepsy. Epilepsia 2011;52:e75-e78.

14. Adewuya AO, Oseni SB. Impact of psychiatric morbidity on parentrated quality of life in Nigerian adolescents with epilepsy. Epilepsy Behav 2005;7:497-501.

15. Malhi P, Singhi P. Correlates of quality of life with epilepsy. Indian J Pediatr 2005;72:131-135.

16. Ronen GM, Streiner DL, Rosenbaum P; Canadian Pediatric Epilepsy Network. Health-related quality of life in children with epilepsy: development and validation of self-report and parent proxy measures. Epilepsia 2003;44:598-612.

17. Verhey LH, Kulik DM, Ronen GM, Rosenbaum P, Lach L, Streiner DL, et al. Quality of life in childhood epilepsy: what is the level of agreement between youth and their parents? Epilepsy Behav 2009;14: 407-410.

18. Hamiwka L, Singh N, Niosi J, Wirrell E. Perceived health in children presenting with a "first seizure. Epilepsy Behav 2008;13:485-488.

19. Baca CB, Vickrey BG, Hays RD, Vassar SD, Berg AT. Differences in child versus parent reports of the child's health-related quality of life in children with epilepsy and healthy siblings. Value Health 2010;13:778-786.

20. Ronen GM, Streiner DL, Rosenbaum P. Health-related quality of life in childhood epilepsy: moving beyond 'seizure control with minimal adverse effects'. Health Qual Life Outcomes 2003;1:36.

21. Austin JK, Risinger MW, Beckett LA. Correlates of behavior problems in children with epilepsy. Epilepsia 1992;33:1115-1122.

22. Kim JW, Park KH, Cheon KA, Kim BN, Cho SC, Hong KE. The child behavior checklist together with the ADHD rating scale can diagnose ADHD in Korean community-based samples. Can J Psychiatry 2005;50: 802-805.

23. Ahn CM, Ebesutani C, Kamphaus R. A psychometric analysis and standardization of the Behavior Assessment System for Children-2, Self-Report of Personality, Child Version among a Korean sample. Sch Psychol Q 2014;29:198-212.

24. John K. Measuring children's social functioning. Child Psychol Psychiatr Rev 2001;6:181-188.

25. Freilinger M, Reisel B, Reiter E, Zelenko M, Hauser E, Seidl R. Behavioral and emotional problems in children with epilepsy. J Child Neurol 2006;21:939-945.

26. Keene DL, Manion I, Whiting S, Belanger E, Brennan R, Jacob P, et al. A survey of behavior problems in children with epilepsy. Epilepsy Be- hav 2005;6:581-586

27. Tse E, Hamiwka L, Sherman EM, Wirrell E. Social skills problems in children with epilepsy: prevalence, nature and predictors. Epilepsy Behav 2007;11:499-505.

28. McEwan MJ, Espie CA, Metcalfe J, Brodie MJ, Wilson MT. Quality of life and psychosocial development in adolescents with epilepsy: a qualitative investigation using focus group methods. Seizure 2004;13:15-31.

29. Elliott IM, Lach L, Smith ML. I just want to be normal: a qualitative study exploring how children and adolescents view the impact of intractable epilepsy on their quality of life. Epilepsy Behav 2005;7:664-678.

30. Bishop M, Allen CA. The impact of epilepsy on quality of life: a qualitative analysis. Epilepsy Behav 2003;4:226-233.

31. Sample PL, Ferguson PL, Wagner JL, Elisabeth Pickelsimer E, Selassie AW. Experiences of persons with epilepsy and their families as they look for medical and community care: a focus group study from South Carolina. Epilepsy Behav 2006;9:649-662.

32. Wilde M, Haslam C. Living with epilepsy: a qualitative study investigating the experiences of young people attending outpatients clinics in Leicester. Seizure 1996;5:63-72.

33. Rhodes PJ, Small NA, Ismail H, Wright JP. 'What really annoys me is people take it like it's a disability', epilepsy, disability and identity among people of Pakistani origin living in the UK. Ethn Health 2008;13: $1-21$.

34. Raty LK, Larsson G, Starrin B, Larsson BM. Epilepsy patients' conceptions of epilepsy as a phenomenon. J Neurosci Nurs 2009;41:201-210.

35. Kilinc S, Campbell C. "It shouldn't be something that's evil, it should be talked about": a phenomenological approach to epilepsy and stigma. Seizure 2009;18:665-671.

36. Westbrook LE, Bauman LJ, Shinnar S. Applying stigma theory to epilepsy: a test of a conceptual model. J Pediatr Psychol 1992;17:633-649.

37. Asato MR, Manjunath R, Sheth RD, Phelps SJ, Wheless JW, Hovinga $\mathrm{CA}$, et al. Adolescent and caregiver experiences with epilepsy. J Child Neurol 2009;24:562-571.

38. Devinsky O, Westbrook L, Cramer J, Glassman M, Perrine K, Camfield C. Risk factors for poor health-related quality of life in adolescents with epilepsy. Epilepsia 1999;40:1715-1720.

39. Baker GA, Hargis E, Hsih MM, Mounfield H, Arzimanoglou A, Glauser T, et al. Perceived impact of epilepsy in teenagers and young adults: an international survey. Epilepsy Behav 2008;12:395-401.

40. Lu L, Gilmour R. Culture and conceptions of happiness: individual oriented and social oriented swb. J Happiness Stud 2004;5:269-291.

41. Park N, Huener ES. A cross-sectional study of the levels and correlates of life satisfaction among adolescents. J Cross Cult Psychol 2005;36:444-456.

42. Austin JK, Dunn DW, Caffrey HM, Perkins SM, Harezlak J, Rose DF.Recurrent seizures and behavior problems in children with first recognized seizures: a prospective study. Epilepsia 2002;43:1564-1573.

43. Kolahi AA, Tahmooreszadeh S. First febrile convulsions: inquiry about the knowledge, attitudes and concerns of the patients' mothers. Eur J Pediatr 2009;168:167-171.

44. Nwokocha EE, Awomoyi AO. Factors influencing mothers' role in convulsion treatment among under-five children in Ibadan, Nigeria. World Health Popul 2009;11:15-29.

45. Yong L, Chengye J, Jiong Q. Factors affecting the quality of life in childhood epilepsy in China. Acta Neurol Scand 2006;113:167-173.

46. Eom S, Eun SH, Kang HC, Eun BL, Nam SO, Kim SJ, et al. Epilepsyrelated clinical factors and psychosocial functions in pediatric epilepsy. Epilepsy Behav 2014;37:43-48.

47. Ryu HU, Lee SA, Eom S, Kim HD; Korean QoL in Epilepsy Study Group. Perceived stigma in Korean adolescents with epilepsy: effects of knowledge about epilepsy and maternal perception of stigma. Seizure 2015;24:38-43.

48. Jensen PS, Watanabe H. Sherlock Holmes and child psychopathology assessment approaches: the case of the false-positive. J Am Acad Child Adolesc Psychiatry 1999;38:138-146. 